\title{
Visceral Hypersensitivity in Non-erosive Reflux Disease: Neurogenic Overwhelming in Esophagus?
}

\author{
Chien-Lin Chen
}

Received: 30 May 2013/Accepted: 5 June 2013/Published online: 29 June 2013

(C) Springer Science+Business Media New York 2013

The mechanism underlying the pathogenesis of heartburn and chest pain in gastro-esophageal reflux disease (GERD) has not been clearly established. An important advance in understanding how heartburn is experienced has been accomplished with the reporting of dilated intracellular spaces (DIS) in the esophageal mucosa of patients with erosive GERD and non-erosive reflux disease (NERD) [1]. Although the presence of DIS provides a theoretical pathway for direct entry of hydrogen ions into the mucosa [2], its relationship to esophageal barrier function is still controversial since there are no direct measurements of esophageal acid permeability in vivo to support its contribution to barrier function. Another important breakthrough is the detection of transient receptor potential vanilloid subfamily member- 1 receptors (TRPV1) in the esophageal mucosa [3], which may potentially contribute to visceral hypersensitivity as one of the important mechanisms in patients with NERD [4]. This notion is supported by the observation that perception of heartburn and esophageal sensitization can be induced by TRPV1 activation after the exposure to capsaicin and related TRPV1 activators such as heat and acid [5]. TRPV1 activation has also been hypothesized to induce neurogenic inflammation by the release of substance $\mathrm{P}$ and calcitonin-gene-related peptide (CGRP) in primary afferent neurons [6]. These neuropeptides mediate nociception and neurogenic inflammation via neurokinin 1 receptor (NK1R) for substance $\mathrm{P}$ and receptor activity-modifying protein 1 (RAMP1) for CGRP [7-9].

\section{C.-L. Chen ( $\square)$}

Department of Medicine, Buddhist Tzu Chi General Hospital and Tzu Chi University, 707, Section 3, Chung-Yang Road, Hualien 970, Taiwan

e-mail: harry.clchen@msa.hinet.net
Therefore, the upregulation of TRPV1 expression in the esophageal mucosa is likely explanation for the phenomenon of visceral sensitization in NERD. Moreover, an induction of proteinase-activated receptor-2 (PAR-2) expression was reported in the esophageal mucosa of GERD patients, which correlated well with mucosal inflammatory changes and elevated tissue interleukin (IL)-8 concentrations, providing a possible mechanism for proinflammatory changes in GERD [10]. Furthermore, PAR-2 also mediates nociception via the release of substance $\mathrm{P}$ [11]. Finally, although anion-sensing ion channels (ASICs) have been implicated in the chemosensitivity in primary afferent fibers [12], its clinical implication is yet unclear in GERD and is thought to be more likely referred to the mechanosensitivity of the esophagus.

In this issue of Digestive Diseases and Sciences [13], Yoshida et al. test the hypothesis regarding the role of nociceptors and neuropeptides in the pathogenesis of visceral hypersensitivity of NERD by examining the expression of acid-sensitive nociceptors including TRPV1, ASIC3, PAR-2, and neuropeptides such as substance $\mathrm{P}$ and CGRP with their cognate receptors NK1R and RAMP1 in the esophageal mucosa of NERD patients as compared with age-matched healthy controls. Not surprisingly, increased mRNA expression for TRPV1 and PAR-2 was present in the esophageal mucosa of NERD patients accompanied by a similar increase in substance $\mathrm{P}$ protein level and mRNA of its receptor NK1R. They also reported the presence of substance P-positive and CGRP-positive nerves in lamina propria of the esophageal mucosa of their patients by immunohistochemistry. They reported a positive correlation between substance $\mathrm{P}$ protein level and acid reflux score. Their data suggest that visceral hypersensitivity in NERD patients appears to be related to nociception and neurogenic inflammation, which supports their hypothesis 
that substance P and NK1R may be implicated in heartburn perception of NERD patients.

One of the major limitations of this study is the definition of NERD, since the diagnosis was primarily made by endoscopic examination, without the addition of 24-h $\mathrm{pH}-$ metry which would help confirm the diagnosis of symptomatic reflux, which is needed to distinguish NERD from hypersensitive esophagus or functional dyspepsia. Moreover, the response to acid suppression therapy was not reported. Therefore, the possibility of functional heartburn in the reported patients cannot be completely excluded. The type of stimuli that induce esophageal hypersensitivity may differ between patients with NERD and functional heartburn; ideally more selective patient selection may have strengthened their data. Although the increased expression of TRPV1 and PAR-2 were noted in NERD patients, their localization of these proteins in the esophageal mucosa of NERD patients is needed. Although this study reported a positive correlation between acid reflux score and mucosal substance $\mathrm{P}$ abundance in esophageal mucosa, more study involving pH-metry and impedance will be needed to attribute mechanistic importance to this association.

In conclusion, increased expressions of TPRV1 and PAR-2 in esophageal mucosa biopsies obtained from subjects with NERD are suggestive of peripheral mechanisms of the enhanced visceral hypersensitivity, whereas increased tissue mucosal substance $\mathrm{P}$ and NK1R expression serve as important clues to the nociception and neurogenic inflammation thought to be present in NERD. With measurement of these important biomarkers in well-characterized subjects, including those with erosive esophagitis and functional heartburn, the pathogenesis of heartburn symptoms and esophageal neurogenic inflammation can be further elucidated.

\section{References}

1. Caviglia R, Ribolsi M, Maggiano N, et al. Dilated intercellular spaces of esophageal epithelium in nonerosive reflux disease patients with physiological esophageal acid exposure. Am J Gastroenterol. 2005;100:543-548.

2. Barlow WJ, Orlando RC. The pathogenesis of heartburn in nonerosive reflux disease: a unifying hypothesis. Gastroenterology. 2005;128:771-778.

3. Bhat YM, Bielefeldt K. Capsaicin receptor (TRPV1) and non-erosive reflux disease. Eur J Gastroenterol Hepatol. 2006;18:263-270.

4. Knowles $\mathrm{CH}$, Aziz Q. Visceral hypersensitivity in non-erosive reflux disease. Gut. 2008;57:674-683.

5. Kindt S, Vos R, Blondeau K, Tack J. Influence of intra-oesophageal capsaicin instillation on heartburn induction and oesophageal sensitivity in man. Neurogastroenterol Motil. 2009;21:1032-e82.

6. Yiangou Y, Facer P, Dyer NH, et al. Vanilloid receptor 1 immunoreactivity in inflamed human bowel. Lancet. 2001;357:1338-1339.

7. Besson JM. The neurobiology of pain. Lancet. 1999;353:1610-1615.

8. Cottrell GS, Alemi F, Kirkland JG, Grady EF, Corvera CU, Bhargava A. Localization of calcitonin receptor-like receptor (CLR) and receptor activity-modifying protein 1 (RAMP1) in human gastrointestinal tract. Peptides. 2012;35:202-211.

9. Tillisch K, Labus J, Nam B, et al. Neurokinin-1-receptor antagonism decreases anxiety and emotional arousal circuit response to noxious visceral distension in women with irritable bowel syndrome: a pilot study. Aliment Pharmacol Ther. 2012;35:360-367.

10. Kandulski A, Wex T, Monkemuller K, et al. Proteinase-activated receptor-2 in the pathogenesis of gastroesophageal reflux disease. Am J Gastroenterol. 2010;105:1934-1943.

11. Vergnolle N, Bunnett NW, Sharkey KA, et al. Proteinase-activated receptor-2 and hyperalgesia: a novel pain pathway. Nat Med. 2001;7:821-826.

12. Page AJ, Brierley SM, Martin CM, et al. Different contributions of ASIC channels 1a, 2, and 3 in gastrointestinal mechanosensory function. Gut. 2005;54:1408-1415.

13. Yoshida N, Kuroda M, Suzuki T, et al. Role of nociceptors/ neuropeptides in the pathogenesis of visceral hypersensitivity of nonerosive reflux disease. Dig Dis Sci. [Epub ahead of print]. doi: 10.1007/s10620-012-2337-7. 